\title{
Institutional Mechanisms of Selection and Development as a Factor of Increasing the Competitiveness of Scientific Activity: Regional Aspect
}

\author{
Arushan Vartumyan ${ }^{1}$, Tatiana Shebzukhova ${ }^{1}$, Irina Klimenko ${ }^{1}$ \\ ${ }^{I}$ North Caucasian Federal University, Russia \\ "Email: iskl@bk.ru
}

\begin{abstract}
The article discusses the problems of forming a system of relationships between regional universities, as subjects of scientific activity, central government bodies in science and regional power structures. Interest in this issue is due to the polymorphic structure of scientific management bodies, insufficiently effective interaction between regional authorities and universities as the main centres of science in the region, the need for institutional identification of the role and place of the university as a generator of scientific ideas in the region's space. Based on studying the problems of institutionalisation in the field of science, the authors introduced the basic concepts of the subject area of research into scientific circulation, performed a theoretical analysis of the influence of the institutional environment on the competitiveness of regional science, and proposed a conceptual and theoretical approach to the study of regional science. The scientific environment features as an object of institutionalisation are revealed, the study of which made it possible to lay the foundations of the author's system of criteria-based assessment of the level of competitiveness. Recommendations for the formation of tools for increasing the competitiveness of objects and subjects of scientific activity, developed by the authors, can be used to expand the framework of the theory of competitiveness and the theory of management of professional organisations; in the practice of organisational management to monitor the competitiveness of regional science.
\end{abstract}

Keywords: Regional science, Competitiveness, Institutionalisation, Selection and development mechanisms.

\section{INTRODUCTION}

The idea of integrating Russian science into the international scientific community requires the use of generally accepted criteria for evaluating the effectiveness of the contribution that Russian science makes to the practice of world scientific research. The digitalisation of space and the processes of globalisation, on the one hand, change the degree of rigidity of borders in scientific research, increase access to information resources and research results; on the other hand, the integration of Russian science into the system of the world scientific space requires high competitiveness and, as a result, the internal transformation of the mechanisms for managing the competitiveness of scientific research. It is hardly advisable to adapt the main provisions of classical competition theories to scientific research and its results as objects of competitive relations. Voloshin A.V. and Alexandrov Yu.L. argue that "the key feature of perfect competition is a company's ability to influence the price level in the market. The absence of this possibility allows us to recognise the market as a market of perfect competition, the presence of the ability to influence prices is a sign of the market of imperfect competition" [1]. The analysis of the evolution of competition theories presented in the foreign authors' works [2] suggests that new approaches are needed to assess science competitiveness. From the point of view of P. Sgaaffa, "when we have a theory for each of the two extreme cases - perfect competition and monopoly, which is only part of the "equipment" necessary to study the real conditions of activity in various industries, we cannot help but realise that these conditions usually do not correspond precisely to any of our categories, but are 
somewhere" in the intermediate zone" and that the nature of a certain industry can approximately relate to production under monopoly or competition based only on its specific characteristics" [3]. Today, the problem of correctly determining the competitiveness of science, creating institutional mechanisms for the selection and development of promising areas is relevant for the subjects of scientific activity, since the quality of the institutional environment is a determining factor in creating effective mechanisms for organising the management of processes occurring in the scientific community [4]. The purpose of the research is to analyse the existing methodological approaches to forming the institutional environment, identify the main problems in the institutionalisation of the scientific community's interaction at different levels, and assess the possibilities of improving regional science competitiveness.

\section{MAIN PART}

\subsection{The degree of scientific development of the problem}

According to E. Durkheim, "if we are talking about facts in the proper sense, then when we start their scientific research, they are necessarily unknown, unknown things for us, since the ideas about them that have arisen in life, formed without methodological and critical analysis, are devoid of scientific value and must be eliminated" [5].

The issues of universities' self-determination, the identification of education as a public good, fair or service have always attracted scientists' attention. Directly opposite models of the university, built by W. von Humboldt and B. Clark, the concept of "academic capitalism" by S. Slaughter and L. Leslie, works by M.K. Petrov, the problems of institutionalisation of science and higher education are at the heart of modern research.

\subsection{Materials and methods}

The study and comparative analysis of factual and empirical materials on the problems of improving the competitiveness of regional science [6], carried out by the authors, allowed us to form a conceptual and theoretical approach to the analysis of the features of regional scientific communities concentrated in the higher education system. The author's approach ensures the unity of institutional, moral and ethical, economic, sociopolitical factors that determine the quantitative and qualitative characteristics of regional science competitiveness. Content analysis of political and legal materials on the subject under study carried out during the study, observation and expert assessment of interaction in the system "university/university sciencecentre" and "university-regional authorities" showed that the need to determine and consolidate the status of each stakeholder in the process of institutionalisation.

From the point of view of Gershman M.A. and Kuznetsova T.E., "one of the key problems of the development of science in Russia remains the lack of productivity of the research and development sector, due to ... lack of incentives and conditions for successful research at the level of organisations, teams, and individual employees" [7]. The terminological cocktail present in modern theories and methodological approaches to the definition of the concept of "competitiveness" confirms the need for a unified approach to the definition of the object of research. Analysing the most common definitions of the competitiveness of an employee, goods, a particular industry, or a country [8-10], the authors note that the functional approach does not provide an opportunity to establish a link between the competitiveness of science and the institutionalisation of the processes of integration of domestic scientific research into the international scientific community.

The regional scientific community, having a certain socio-political status, having limited human, financial, and other resources, strives to effectively fulfil its mission to increase intellectual resources, increase national wealth, and stimulate the development of priority areas of science, thereby increasing the competitiveness of the region and the country [11-12].

\section{STUDY RESULTS AND DISCUSSION}

The heuristic possibilities of the conceptualtheoretical approach to the development of institutional mechanisms of selection and development as a factor of increasing the competitiveness of regional science are revealed. The basic concepts are clarified, the tools for managing the competitiveness of scientific activity are proposed: the term competitiveness of objects/subjects of scientific activity is understood as a generalised characteristic that can be expressed by an integral indicator (KP). The integral indicator includes the register of the estimated parameters having the final value $m$, the reference value for each of the parameters of the Piet, the result of comparing the estimated parameter of the object Pi with the standard for each of the evaluation parameters, the rank of the evaluated object in the system of scientific research ri (formula 1):

$\mathrm{KP}=\sum_{\mathrm{i}=1}^{\mathrm{m}} \mathrm{Pi} /$ Piet $^{*} \mathrm{r}_{\mathrm{i}}$

where - KP is an integrated assessment of competitiveness;

$\mathrm{m}$ - the number of estimated parameters;

$\mathrm{P}_{\text {iet }}$ - the reference value of the estimated parameter;

$P_{i}$ - the value of the object parameter to be evaluated; 
$\mathrm{r}_{\mathrm{i}}$ - the rank of the object, determined by the method of expert assessments [13].

Considering the competitiveness of science as a complex indicator, it is advisable to talk about creating an institutional environment for effective evaluation of the quality of scientific research, the results obtained at different levels, and the degree of influence on the regional, sectoral, and national economy [14]. The authors argue that the solution at the institutional level of the problem of differentiation of scientific research requires creating a regulatory and legislative framework for assessing the competitiveness of objects/subjects of scientific activity based on objective quantitative indicators. The following definition is proposed: the institutional mechanism of selection and development is a set of norms and rules for dividing a set into subsets under a given system of criteria, choosing an alternative with given properties.

Today, the institutional environment in which the scientific community is "immersed" is built according to hierarchical principles, while for the transition from one level of the hierarchy to another, certain formal requirements must be met [15]. Examples accompanying this statement are the Regulations on the Procedure for Awarding Academic Degrees/Titles and other normative acts. In some cases, the functions of institutional selection mechanisms are performed by expert groups formed according to the degree of compliance with formal requirements, for example, expertise in the Russian Foundation for Basic Research; in the Ministry of Science and Higher Education when determining the performers of target programs; in sectoral or regional ministries when allocating research grants, etc. The author's development of correct selection mechanisms for individual scientific research, groups of researchers and/or research areas, schools for delegating them to the next, higher level allows monitoring the processes of interaction between the institutional environment and the regional scientific community, improving the selection system, thereby contributing to the integration of domestic science into the international scientific community.

\section{CONCLUSIONS}

The conducted research has shown that methodological approaches to the institutionalisation of the scientific sphere are far from perfect, despite the variety of ideas and opinions of specialists studying this problem. The fact is that in the presence of intellectual and labour resources, domestic science in the regions has an insufficiently high level of competitiveness requires solving a complex of tasks of the organisational, economic and institutional order. Thus, it becomes obvious that it is expedient to restructure the existing scientific management system to create a new infrastructure capable of delegating functions unrelated to scientific activities specialising in scientific ideas commercialisation. Institutional mechanisms regulating relations between the scientific and business community should contribute to solving several organisational problems that affect the correct determination of the actual level of competitiveness of subjects and objects of scientific activity, the effectiveness of interaction of regional science with the centre, and the authorities in the region.

\section{REFERENCES}

[1] A.V. Voloshin, Yu.L. Alexandrov, Evolution of the theory of competition and competitiveness in economic science, Fundamental research 4-2 (2017) 330-338. Retrieved from: http://fundamentalresearch.ru/ru/article/view?id=41483 (date accessed: 24.11.2020).

[2] J. Robinson, Economic theory of imperfect competition, M.: Progress, 1986, 472 p.

[3] P. Sgaaffa. The Laws of Returns under Competitive Conditions, Economic Journal, December 1926, p. 542.

[4] A.I. Kovalenko, Theoretical and methodological aspects of using the concept of competitiveness in scientific research, Competition theory 2 (2013) 6579.

[5] E. Durkheim, Sociology, Its subject, method, purpose, Per. from French, compilation, afterword and notes by A.B. Hoffman, Moscow: Canon, 1995, $352 \mathrm{p}$.

[6] N.A. Shmatko, Yu.L. Kachanov, The effectiveness of research team management, M.: University book, 2010, 176 p.

[7] M.A. Gershman, T.E. Kuznetsova, Effective contract in science: model parameters, Foresight Vol. 7. Iss. 3 (2013) 26-37.

[8] Science and knowledge: competitiveness of society, science and business in the context of world integration processes, Materials of the international scientific and practical conference. Edited by V.V. Ponomareva, T.A. Kutkovich, Publisher: Moscow Humanitarian and Economic Institute, Novorossiysk Branch, 2017, 240 p.

[9] N.G. Bondarenko, T.A. Shebzuhova, P.A. Petryakov, L.Y. Manahova et al. The quality criteria of training of specialists in the context of the competence approach, Modern journal of language teaching methods Vol. 9, Iss. 1 (2019) 353-364.

[10] M.G. Sergeeva, N.G. Bondarenko, A.A. Vartumyan et al. Scientific substantiation of the Conception of continuous economic education development, The 
Turkish Online Journal of Design, Art and Communication - TOJDAC, March 2018 Special Edition, pp. 178-185.

[11] Shadieva D. Analysis of global trends in financing innovative activities, World and national economy, Iss. 2(37), 2016 [Electronic resource]. Retrieved from: http://mirec.ru/2016-02/analiz-mirovykhtendentsiyfinansirovaniya-innovatsionnoydeyatelnosti

[12] Science and Engineering Indicators 2016, Chapter 4, Research and Development: National Trends and International Comparisons [Electronic resource]. Retrieved from: https://www.nsf.gov/statistics/2016/nsb20161/ uploads/1/7/chapter-4.pdf (date accessed: 23.11.20).

[13] A.A. Vartumyan, I.S. Klimenko, Methods of mathematical modelling in the management of socio-political processes: the theory of queuing, Scientific journal Caspian region: politics, economics, culture 3(64) (2020) 55-61.

[14] I.S. Klimenko, P.F. Klimenko, Mathematical model and methodology for assessing the investment attractiveness of the region, Influence of the new geopolitical reality on public administration and development of the Russian Federation: Materials of the II All-Russian scientific and practical Conf.Grozny: Publishing house of ChGU, 2019, pp. 179183.

[15] D. Rodrik, Institutions for high-quality growth: what they are and how to acquire them, D. Rodrik, Institutions, globalisation and empowerment/ed. by K. C. Roy, J. Sideras, Cheltenham: Edward Elgar Publishing 2 (2006) 19-55. 